\title{
AN INEQUALITY FOR DISTANCES AMONG FIVE POINTS AND DISTANCE PRESERVING MAPPINGS
}

\author{
SOON-MO JUNG AND DOYUN NAM
}

Abstract. Using properties of norm and inner product, we prove a new inequality for distances between five points arbitrarily given in an inner product space. Moreover, we investigate the Aleksandrov-Rassias problem by proving that if the distance 1 is contractive and the golden ratio is extensive by a mapping $f$, then $f$ is a linear isometry up to translation.

Mathematics subject classification (2010): 51M16, 51K99, 51K05, 46C99.

Keywords and phrases: Inequalities, Aleksandrov-Rassias problem, distance, linear isometry, point.

\section{REFERENCES}

[1] A. D. Aleks androv, Mapping of families of sets, Soviet Math. Dokl. 11 (1970), 116-120.

[2] F. S. Beckman And D. A. Quarles, On isometries of Euclidean spaces, Proc. Amer. Math. Soc. 4 (1953), 810-815.

[3] W. BENZ, Isometrien in normierten Räumen, Aequationes Math. 29 (1985), 204-209.

[4] W. BenZ AND H. Berens, A contribution to a theorem of Ulam and Mazur, Aequationes Math. 34 (1987), 61-63.

[5] S.-M. JUNG, Inequalities for distances between points and distance preserving mappings, Nonlinear Anal. 62 (2005), no. 4, 675-681.

[6] S.-M. Jung AND K.-S. LEE, An inequality for distances between $2 n$ points and the AleksandrovRassias problem, J. Math. Anal. Appl. 324 (2006), no. 2, 1363-1369.

[7] J. MAtoušEK, Lectures on Discrete Geometry, Grad. Texts in Math., vol. 212, Springer, New York, 2002.

[8] TH. M. RASSIAS, Is a distance one preserving mapping between metric spaces always an isometry? Amer. Math. Monthly 90 (1983), 200.

[9] TH. M. RAssias, Mappings that preserve unit distance, Indian J. Math. 32 (1990), 275-278.

[10] TH. M. RAssias, Properties of isometries and approximate isometries, in Recent Progress in Inequalities (ed. G. V. Milovanovic), pp. 341-379, Kluwer, 1998.

[11] S. XIAng, Mappings of conservative distances and the Mazur-Ulam theorem, J. Math. Anal. Appl. 254 (2001), 262-274. 